\title{
Increases in Excitability of Neurons of the Motor Cortex of Cats after Rapid Acquisition of Eye Blink Conditioning
}

\author{
Shuji Aou, ${ }^{a}$ Charles D. Woody, and Dorwin Birt \\ Mental Retardation Research Center, Brain Research Institute, UCLA Medical Center, Los Angeles, California 90024
}

\begin{abstract}
Measurements were made of resting potentials, input resistance, and excitability to intracellularly applied, depolarizing current pulses in neurons of the pericruciate cortex of conscious cats before and after acquisition of a rapidly conditioned eye blink reflex (CR). Neuronal excitability increased after conditioning, and an increased input resistance was found to be correlated with the increased level of excitability. No associated changes were found in resting potentials as a consequence of conditioning.

When cells were divided into groups according to the latency of spike activity elicited by a click conditioned stimulus (CS) in relation to four separate excitatory EMG components of the compound blink CR, excitability increases were found in cells with increased spike activity at $\alpha_{1}$ (8-40 msec), $\alpha_{2}$ (40-72 msec), $\beta$ (72-112 $\mathrm{msec})$, and $\gamma(112-160 \mathrm{msec})$ latencies after delivery of the CS. Also, the proportion of cells with high excitability ( $<0.7 \mathrm{nA}$ required for spike elicitation) was increased at each latency period after conditioning. Increases in later components of spike discharge could also be found in the cells with increases in earlier components of discharge and increased excitability. The findings suggested that excitability increases facilitated a responsiveness to the CS that supported production of long- as well as short-latency components of the blink CR.

Many of the changes in neuronal properties found after rapid eye blink conditioning, such as the increases in excitability and resistance and in the proportion of CS-excitable cells, resembled changes found earlier after acquisition of a slowly developing Pavlovian blink CR, using the same click CS and tap unconditioned stimulus without addition of a hypothalmic stimulus. The possibility should be considered that the (10-100 times) more rapidly acquired form of eye blink conditioning does not represent a different form of conditioning, but instead a change in the rate of conditioning supported by the more rapid production of increases in neural excitability.
\end{abstract}

\footnotetext{
Received Mar. 18, 1991; revised Sept. 16, 1991; accepted Sept. 24, 1991.

This research was supported by HD 05958; the Japan Ministry of Culture, Education and Science; and the Sasakawa Fund. We thank Dr. R. Little for advice on statistical analysis of the data and E. Gruen, I. Feng, and R. Shori for technical help with data analysis. We also thank Drs. O. Hikosaka and Z. Karádi for their comments on the manuscript.

Correspondence should be addressed to Dr. C. D. Woody, UCLA Medical Center, Room 58-232, NPI, 760 Westwood Plaza, Los Angeles, CA 90024.

a Present address: Department of Physiology, Faculty of Medicine, Kyushu University, Fukuoka 812, Japan.

Copyright (C) 1992 Society for Neuroscience $0270-6474 / 92 / 120560-10 \$ 05.00 / 0$
}

Recent evidence suggests that the essential adaptive mechanisms supporting Pavlovian conditioning of long-latency $[>100$ msec onset after delivery of conditioned stimulus (CS)] nictitating membrane and eye blink responses may be found in neurons of the cerebellum and brain stem (Moore et al., 1982; Yeo et al., 1984; Thompson, 1986). Earlier investigations (Woody and Black-Cleworth, 1973; Woody et al., 1976; Brons and Woody, 1980), however, found increases in the excitability of neurons of the cortex after Pavlovian conditioning of a shortlatency eye blink reflex. The short, $\alpha$-latency of that response raised questions about its generality as a model of conditioning (Hilgard and Marquis, 1940; Thompson and Donegan, 1987; but cf. Woody, 1982, 1986), and the conditioned reflex (CR) was acquired slowly, 700-1000 trace pairings of click CS and glabella tap unconditioned stimulus (US) being required for its development (Woody et al., 1974; Woody, 1982). Consequently, a model of rapid conditioning was sought with both short- and long-latency response components (Kim et al., 1983; Hirano et al., 1987).

A preceding report (Hirano et al., 1987) provided evidence that an eye blink reflex with both short- and long-latency components could be conditioned rapidly in 20 or fewer pairings using the same click CS and tap US with addition of electrical stimulation of the hypothalamus (HS). Subsequently, the pattern of activity elicited in cells of the motor cortex by the CS was found to change after conditioning in such a way as to support production of each component of the conditioned response (Aou et al., 1992). Further studies, described in this report, determined if changes in membrane properties occurred in these cortical neurons that could support the enhancement of unit activity.

Intracellular recordings were obtained from neurons of the motor cortex of conscious cats before and after development of the blink CR. Resting potentials (RP) and input resistance $\left(R_{N}\right)$, as well as excitability to depolarizing current pulses, were measured. The following questions were asked. (1) Was neuronal excitability increased after rapid conditioning? (2) Did development of the changes depend on the order of stimulus pairing, as did development of the conditioned behavioral response? (3) Was excitability increased in cells with long- as well as shortlatency responses to the CS? (4) Were changes in resting potential or input resistance correlated with the changes in neuronal excitability? (5) Were changes in membrane properties after conditioning found selectively in neurons classified according to their receptivity to the $\mathrm{CS}$, or were they found more selectively in neurons classified according to their motor projection to muscles involved in generation of the CR? 
Table 1. Average excitability ${ }^{a}$ by cat and behavioral state

\begin{tabular}{|c|c|c|c|c|c|c|c|}
\hline \multirow{2}{*}{ Cat } & & \multicolumn{6}{|c|}{ Behavioral state } \\
\hline & & $\overline{\mathrm{ADP}}$ & COND & EXT S $^{+}$ & EXT S $^{-}$ & $\mathrm{DHS}_{0}$ & $\mathrm{DHS}_{c}$ \\
\hline \multirow[t]{3}{*}{$\mathrm{N}$} & Mean & 0.82 & 0.64 & 0.73 & & & 0.76 \\
\hline & $n$ & 21 & 53 & 26 & & & 20 \\
\hline & SD & 0.59 & 0.36 & 0.35 & & & 0.35 \\
\hline \multirow[t]{3}{*}{$\mathrm{F}$} & Mean & 0.97 & 0.69 & 0.65 & & & 0.78 \\
\hline & $n$ & 22 & 65 & 33 & & & 19 \\
\hline & $\mathrm{SD}$ & 0.50 & 0.49 & 0.29 & & & 0.47 \\
\hline \multirow[t]{3}{*}{ G } & Mean & 0.84 & 0.68 & & & & 0.40 \\
\hline & $n$ & 27 & 13 & & & & 2 \\
\hline & SD & 0.27 & 0.30 & & & & 0.00 \\
\hline \multirow[t]{3}{*}{ I } & Mean & 0.78 & 0.49 & & & & \\
\hline & $n$ & 4 & 5 & & & & \\
\hline & SD & 0.13 & 0.13 & & & & \\
\hline \multirow[t]{3}{*}{$\mathrm{H}$} & Mean & 1.2 & 0.63 & & & & \\
\hline & $n$ & 7 & 17 & & & & \\
\hline & SD & 0.66 & 0.28 & & & & \\
\hline \multirow[t]{3}{*}{ A } & Mean & 1.11 & 0.70 & & 0.85 & & \\
\hline & $n$ & 22 & 18 & & 32 & & \\
\hline & SD & 0.62 & 0.37 & & 0.48 & & \\
\hline \multirow[t]{3}{*}{ B } & Mean & 0.88 & & & 0.92 & & \\
\hline & $n$ & 20 & & & 28 & & \\
\hline & SD & 0.40 & & & 0.56 & & \\
\hline \multirow[t]{3}{*}{$\mathrm{O}$} & Mean & 0.99 & & & 0.86 & & \\
\hline & $n$ & 24 & & & 31 & & \\
\hline & SD & 0.43 & & & 0.45 & & \\
\hline \multirow[t]{3}{*}{$\mathrm{E}$} & Mean & 1.09 & & & & 0.99 & \\
\hline & $n$ & 20 & & & & 31 & \\
\hline & $\mathrm{SD}$ & 0.56 & & & & 0.46 & \\
\hline \multirow[t]{3}{*}{$\mathrm{C}$} & Mean & 0.93 & & & & 0.78 & \\
\hline & $n$ & 21 & & & & 21 & \\
\hline & $\mathrm{SD}$ & 0.44 & & & & 0.33 & \\
\hline Total & $n$ & 188 & 171 & 59 & 91 & 52 & 41 \\
\hline
\end{tabular}

ADP, adaptation; COND, conditioning; EXT S+, prolonged extinction with performance of CRs; EXT S-, prolonged extinction without performance of CRs (full extinction); DIS $_{0}$, delayed IIS presentation without prior conditioning; DHS $_{c}$, delayed HS presentation after prior conditioning. $n$, Number of cells. (See Results for $F$ test of data and Table 2 for analyses of within-cat differences in means.)

- Magnitude of intracellularly applied depolarizing current, in nanoamperes, required to elicit spikes.

\section{Materials and Methods}

The present animals provided most of the data in the preceding article (cf. Table 1, below, versus Table 1 of Aou et al., 1992). The animals, which were initially naive to the procedures, were given adaptation and rapid conditioning sessions with click CS, tap US, and hypothalamic electrical stimulation (HS); for further details of behavioral protocols, placement of hypothalamic stimulating electrodes and histology, and patterns of unit activity elicited by CS and HS, please see Aou et al. (1992). [Also see Woody et al. (1991) for evidence that rapid conditioning of cortical units can be accomplished by local ionophoretic application of glutamate, intracortically, in lieu of HS.]

A detailed description of the methods used to obtain intracellular recordings from the pericruciate cortex of conscious cats was given in the preceding article (Aou et al., 1992; also see Woody and BlackCleworth, 1973; Woody et al., 1984). The resistances of glass recording electrodes filled with $3 \mathrm{~m} \mathrm{KCl}$ ranged from 15 to $40 \mathrm{M} \Omega$. Capacilance compensation of each electrode was adjusted after insertion into the cortex before intracellular penetration. The time constant of the electrodes was brief enough $(<0.5 \mathrm{msec})$ to be easily distinguished from that of penetrated cells. Membrane properties were analyzed in cells in which hyperpolarizing current was not needed to maintain stability After penetrating each cell (and balancing the Wheatstone bridge to null electrode resistance), neuronal excitability was determined as the thresh- old level of current required to elicit spike activity using $20 \mathrm{msec}$ depolarizing current pulses. The satisfactory condition of the studied cells was indicated by the ability to obtain recordings of activity with patterns equivalent to those obtained from extracellularly recorded units (e.g., Fig. 2 of Aou et al., 1992) and by input resistances comparable to those obtained by other investigators from neurons of this region in comparable preparations (Lux and Pollen, 1966; Krnjevic et al., 1971; Baranyi et al., 1988; Berthier and Woody, 1988). Figure $1 A$ shows an intracellular recording from a neuron of a conditioned cat in which spikes were produced at variable latencies with current pulses of 0.15 and $0.3 \mathrm{nA}$ (left) and then were produced at a relatively fixed latency after the onset of pulses of $0.5 \mathrm{nA}$ (right). The value of current that repeatedly elicited spike activity at a relatively fixed latency during 50\% or more of the pulse applications was taken as the threshold current

After measurements of excitability were completed and rates of discharge returned to baseline levels, the RP was measured and, then, the apparent input resistance $\left(R_{N}\right)$ was measured from the IR drops produced by intracellular application of $1.0 \mathrm{nA}$ hyperpolarizing current pulses of 150 msec duration (cf. Creutzfeldt et al., 1964; Koike et al., 1968; Purves, 1981; Stafstrom et al., 1984; Spain et al., 1987). Five measurements of $R_{N}$ during the period $20-50 \mathrm{msec}$ after the beginning of the current pulses were used to calculate the average $R_{N}$ for each cell. Attempts were made to maintain bridge balance of the electrode resis- 

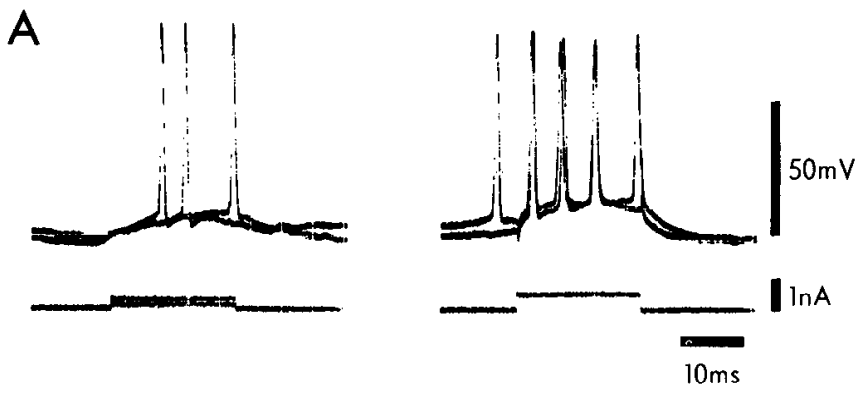

B
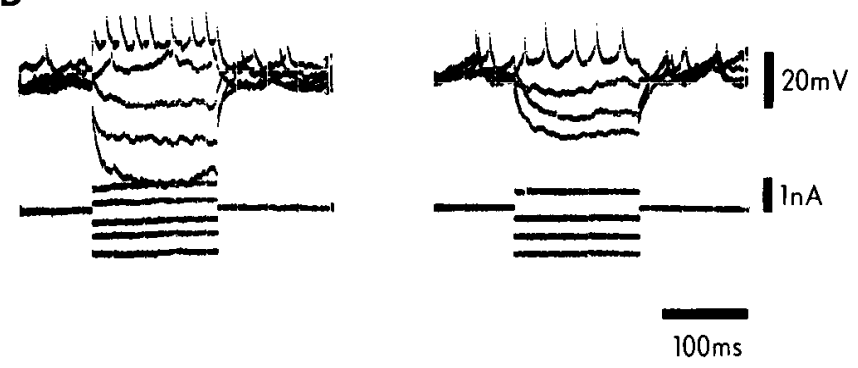

Figure 1. A, Determination of excitability threshold of a cortical neuron with depolarizing current pulses. On the left are shown variablelatency spike potentials in response to intracellularly applied currents of 0.15 and $0.3 \mathrm{nA}$. At the right, a repeatable, fixed-latency spike response was observed to application of a current of $0.5 \mathrm{nA}$. Thresholds were taken as the lowest currents that produced such responses. $B$, Recordings from two neurons showing intracellular application of hyperpolarizing current pulses used to determine input resistance. (Responses to a depolarizing pulse are also shown.) In awake animals, spontaneous postsynaptic potential activity introduces noise into the baselines; therefore, measurements from five pulses per cell were made and averaged to reduce error.

tance during the recordings (Fig. $1 B$, right). When the electrode resistance component was imbalanced (e.g., Fig. $1 B$, left), we later made corrections for the imbalance when determining $R_{N}$. Determinations of input resistance were made from film strips by a blind method in which the identity of the cell and the behavioral state of the animal were not known.

Projections of cells were determined from spike-triggered averages of EMG activity in orbicularis oculi and levator oris muscles as described in detail in an earlier study (Woody and Black-Cleworth, 1973). A cell was classified as projective if EMG activity related to its spike discharges exceeded spontaneous baseline EMG activity. All classifications of motor projection were done by blind analyses, as above.

\section{Results}

Intracellular recordings and tests of excitability with injections of depolarizing current pulses were made in a total of 602 neurons of the motor cortex of 10 awake cats (Table 1). Input resistance measured in 465 of these cells averaged 11.3 $\mathrm{M} \Omega$. Resting potentials of these cells averaged $53.2 \mathrm{mV}$ with action potentials of up to $83 \mathrm{mV}$ in amplitude.

\section{Excitability after conditioning}

Levels of intracellularly applied depolarizing current required for spike initiation were measured before conditioning in 188 cells (10 cats) and after conditioning in 171 separate cells (6 cats) (Table 1). After conditioning, the mean level of current required to elicit spike discharge decreased from $0.96 \pm 0.49$ (SD) to $0.66 \pm 0.40 \mathrm{nA}$. An ANOVA (Winer, 1971) of the lntransformed data from the six conditioned cats found differences in the levels of currents between the naive and conditioned behavioral states $\left(F_{1,262}=26.4 ; p<0.0001\right)$. These differences did not arise from individual animal variability within a given behavioral state $\left(F_{5,262}=1.22 ; p=0.3\right)$. Within-animal comparisons (Fig. 2) showed that levels of current required to elicit spike discharge were significantly lower after conditioning in four of six cats tested ( $p<0.02, t$ test of data within animals before and after conditioning). Levels in the remaining two animals also decreased (Fig. 2, N and G; each $p<0.10$ ). (All tests of significancc wcrc two tailcd unless otherwise specified.)

Extinction and performance of blink CR. Effects on neural excitability of prolonged extinction trials (without interspersed reconditioning) were studied as was the relationship between excitability and the ability to perform the blink CR. [In each cat studied, excitability was measured prior to analysis of (i.e., without knowing) the level of retention of CRs.] After prolonged extinction sessions (mean, 350 trials; see Aou et al., 1992) with continued performance of CRs (EXT S ${ }^{+}$; see Table 1), neural excitability remained significantly increased $(p<0.001, t$ test of difference between means) above levels found before acquisition of the CR (adaptation period) and above levels in animals that underwent comparable periods of extinction (mean, 340 trials) and did not continue to perform blink CRs (EXT S-). A summary of these results is shown in Table 2.

Backward conditioning. Backward conditioning $\left(\mathrm{DHS}_{0}\right.$ and DHS $_{c}$; see Table 1) was less effective than forward conditioning (COND) in inducing changes in neural excitability $(p<0.03$, Fisher test of mean excitability by cat, Table 1, all cats). None of the within-animal comparisons made in four cats (two $\mathrm{DHS}_{0}$ and two $\mathrm{DHS}_{c}$; cat $\mathrm{G}$ of the $\mathrm{DHS}_{c}$ group was excluded due to too few cells) showed significant changes from the naive (ADP) baseline levels of currents required to produce spike discharge (see Table 1).

Extinction-reconditioning. Comparison of data from the first five and last five cells recorded in each conditioned animal showed no differences in the degree of increase in excitability as a function of the amount of reconditioning (means for adaptation: first five, $1.0 \mathrm{nA}$; last five, $1.1 \mathrm{nA}$; conditioning: first five, $0.7 \mathrm{nA}$; last five, $0.6 \mathrm{nA}$ ). Equally significant increases in excitability were found within conditioned animals $(\mathrm{G}, \mathrm{I}, \mathrm{H}, \mathrm{A}$; Table 1) from which small numbers of cells were recorded as compared to animals in which larger numbers of cclls werc recorded (with greater numbers of extinction-reconditioning trials). These data indicated that the increases in excitability occurred rapidly, being detectable in the earliest measurements made after conditioning.

\section{Excitability versus $R_{N}$ and $R P$ after conditioning}

Excitability to intracellularly applied depolarizing current (EXC, Fig. 2), $R_{N}$, and RP were compared as a function of conditioning and other behavioral states (Fig. 2, Table 2). The findings suggested that the increases in excitability and $R_{N}$ after conditioning were interrelated. This was tested by measuring correlation coefficients between these variables in single cells. An inverse correlation was found between levels of threshold currents and $R_{N}$. The Pearson correlation coefficients $(r)$ between measurements of these variables in single cells during adaptation and conditioning were $-0.25(t=1.65 ; p<0.10)$ and $0.31(t=2.01$; $p<0.05$ ), respectively.

The most robust increases in $R_{N}$ occurred after conditioning, relative to other behavioral states. Analysis of differences in mean values of $R_{N}$ (from averages of cells for each cat) revealed an increase of $R_{N}$ averaging $2.0 \mathrm{M} \Omega(20 \%$ increase above adaptation baseline; $p<0.05$, matched $t$ test of difference of means 


\section{CHANGE IN NEURONAL MEMBRANE PROPERTIES BY CAT,} AFTER CONDITIONING

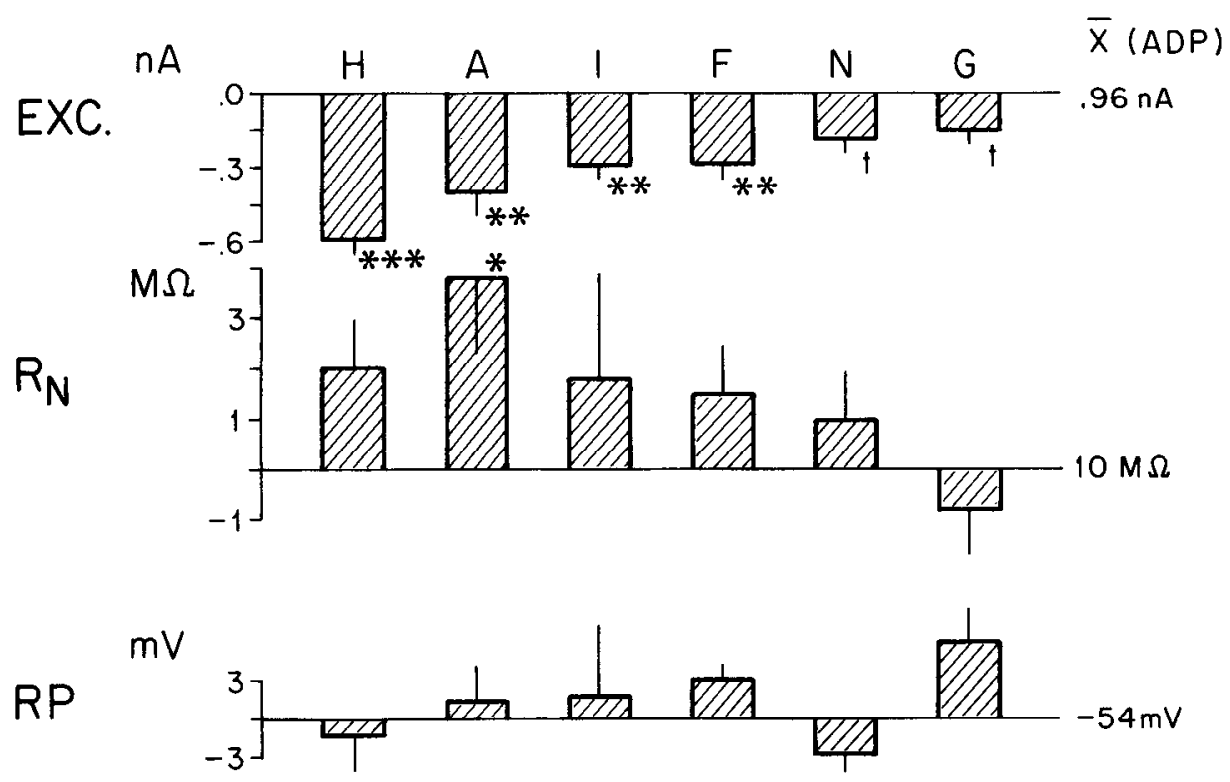

Figure 2. Differences between adaptation and conditioned states in mean values of excitability $(E X C)$, input resistance $\left(R_{N}\right)$, and resting potential $(R P)$ obtained within each of six cats. Thin vertical bars show SEM. Letters identify cats as in Table 1. After conditioning, excitability increased and less current was required for spike initiation $(t \leq$ $0.05 ;^{*} \leq 0.025,{ }^{* *} \leq 0.01,{ }^{* * *} \leq 0.001$, one-tailed values of $p$ ); means for adaptation $[\bar{X}(A D P)]$ are as shown.

within cats) after conditioning (COND, Table 2). There was also a tendency for $R_{N}$ to be increased in cats given backward conditioning following adaptation ( $\mathrm{DHS}_{0}$, Table 2).

Comparisons made within each animal (Fig. 2) showed that five of six cats had a higher mean $R_{N}$ after conditioning than before. A significant increase in $R_{N}$ after conditioning was found by within animal tests in one cat (cat A, Fig. 2), but not by $F$ test across cats $\left(F_{1,224}=1.78 ; p=0.18\right)$. The cat that showed a decrease in mean $R_{N}$ after conditioning showed the smallest increase in excitability (cat G, Fig. 2). This cat also showed the least discriminative CRs.

RPs did not change significantly after conditioning (Table 2, Fig. 2). Figure 3 compares the distributions of RP, $R_{N}$, and action potentials for adaptation and conditioning. (The sizes of action potentials were measured for use as an index of possible sampling bias or cell injury.) The distributions of action potentials as well as RPs were no different before and after conditioning, but the distributions of $R_{N}$ shifted toward higher values after conditioning (Fig. 3, bottom).

In animals given backward conditioning after previous conditioning of blink responses (Table $2, \mathrm{DHS}_{c}$ ), RP became more positive relative to that during adaptation. This change was associated with an increased rate of spontaneous firing (cf. Aou et al., 1992, their Fig. 6, DHS $)$. [Changes in mean RP in the EXT S $^{+}$state (Table 2) were not uniform among individual cats, and levels of spontaneous firing in that state did not differ significantly from the level during adaptation.]

\section{Effects of conditioning on firing patterns and neural excitability within individual cats}

Histogram averages of spike activity showed changes in neuronal firing patterns as a function of conditioning both across cats (e.g., Fig. 3 of Aou et al., 1992) and within individual animals (Fig. 4). In Figure 4, histogram averages of spike activity obtained individually from four cats during adaptation and conditioning are compared with averages of concurrent myographic recordings (orbicularis oculi muscles) of the associated eye blink behavior. After conditioning, peaks of discharge elicited by the CS became larger than during adaptation and preceded rather than followed production of related components of the CR. Increases in neural excitability accompanied the enhancement of unit activity in each animal.

Membrane properties as a function of latency and magnitude of response to $C S$

Latency. Intracellularly recorded units from the animals of Figure 2 were divided into four groups according to the peak latency of spike activity elicited by the CS (Fig. 5). When levels of excitability after conditioning were compared with those during adaptation, excitability increases were found supporting increased spike activity at $\alpha_{1}(8-40 \mathrm{msec} ; p<0.05), \alpha_{2}(40-72$ msec; $p<0.01), \beta(72-112 \mathrm{msec} ; p<0.10)$, and $\gamma(112-160$

Table 2. Differences between adaptation and other behavioral states in levels of mean excitability (EXC), input resistance $\left(R_{N}\right)$, and $R P$

\begin{tabular}{|c|c|c|c|}
\hline $\begin{array}{l}\text { Behavioral } \\
\text { state }\end{array}$ & $\mathrm{EXC}(\mathrm{nA})$ & $R_{N}(\mathrm{M} \Omega)$ & $\mathrm{RP}(\mathrm{mV})$ \\
\hline \multicolumn{4}{|c|}{ CR not performed: } \\
\hline EXT S ${ }^{-}$ & $-0.07 \pm 0.05$ & $0.6 \pm 0.6$ & $-1.6 \pm 1.3$ \\
\hline DHS $_{0}$ & $-0.11 \pm 0.06$ & $1.4 \pm 0.7$ & $2.3 \pm 1.4$ \\
\hline \multicolumn{4}{|c|}{ CR performed: } \\
\hline COND & $-0.28 \pm 0.03^{*}$ & $2.0 \pm 0.5^{*}$ & $0.1 \pm 0.8$ \\
\hline EXT S ${ }^{+}$ & $-0.21 \pm 0.04^{*}$ & $0.2 \pm 0.7$ & $5.9 \pm 1.7^{*}$ \\
\hline \multicolumn{4}{|c|}{$C R$ reduced: } \\
\hline $\mathrm{DHS}_{c}{ }^{a}$ & $-0.13 \pm 0.07$ & $-0.4 \pm 0.9$ & $9.7 \pm 2.2^{*}$ \\
\hline
\end{tabular}



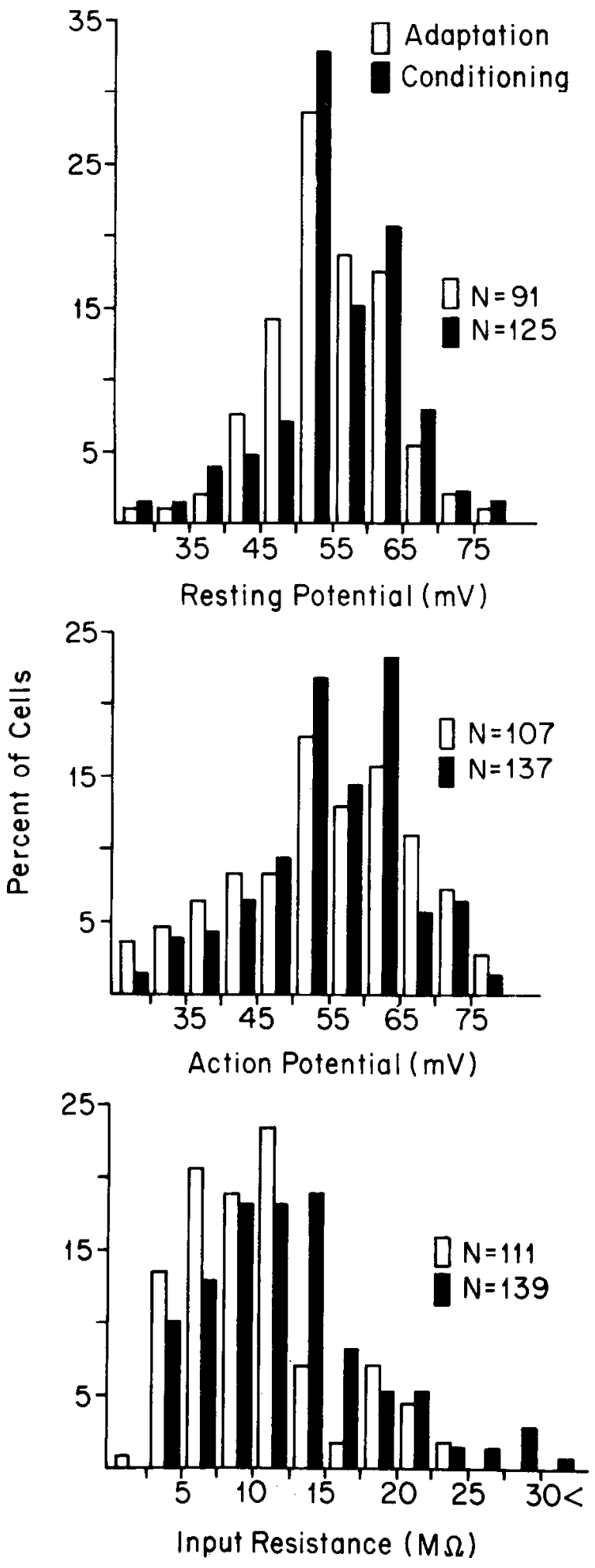

Figure 3. Distributions of RPs, action potentials, and input resistances measured during adaptation and conditioned states. $N$, Number of cells. Bars are placed between the ranges of data they represent, for example, resting potentials of $45-50 \mathrm{mV}$, and so on.
Table 3. Cells classified by level of excitability and magnitude of response to $\mathrm{CS}$

\begin{tabular}{|c|c|c|c|c|c|}
\hline \multirow{2}{*}{$\begin{array}{l}\text { Behavioral } \\
\text { state }\end{array}$} & \multirow{2}{*}{$\begin{array}{l}\text { Excitability } \\
(\mathrm{nA})^{a}\end{array}$} & \multicolumn{3}{|c|}{$\mathrm{CS}$ response } & \multirow[b]{2}{*}{ Total } \\
\hline & & $<2 Z$ & $2-3 Z$ & $>3 Z$ & \\
\hline \multirow[t]{2}{*}{ ADP } & $<0.7$ & 1 & 3 & 4 & 8 \\
\hline & $>0.7$ & 8 & 12 & 19 & 39 \\
\hline \multicolumn{2}{|c|}{ Total number of cells } & 9 & 15 & 23 & 47 \\
\hline \multirow[t]{2}{*}{ COND } & $<0.7$ & 3 & 7 & $22^{*}$ & $32^{*}$ \\
\hline & $>0.7$ & 3 & 6 & 10 & 19 \\
\hline \multicolumn{2}{|c|}{ Total number of cells } & 6 & 13 & 32 & 51 \\
\hline
\end{tabular}

Definitions of behavioral states are as in Table 1 ; magnitude of response to CS is referred to as the number of $Z$ above the pre-CS (spontaneous) baseline firing rate (see text for further details).

a Magnitude of intracellularly applied depolarizing current, in nanoamperes, required to elicit spikes.

${ }^{*}, p<0.01$ ( $x^{2}$ test comparison between adaptation and conditioned state).

msec; $p<0.05$ ) latencies after delivery of the CS (see Aou et al., 1992). The proportion of cells with high excitability $(<0.7$ $\mathrm{nA}$ required for spike elicitation) was increased at each latency period after conditioning $[53 \%, 81 \%, 57 \%, 60 \%$ (conditioning) vs. $16 \%, 27 \%, 25 \%, 0 \%$ (adaptation), respectively]. Increases in later components of spike discharge were also found in the cells with increases in earlier response components (see Aou et al., 1992, their Figs. 2 and 5).

Magnitude. Cells were classified according to their ability to respond to the CS. The level of excitability of 96 cells measured during adaptation or conditioning (two additional cells not included because response was $>15 Z$ above background or threshold current was $>3.0 \mathrm{nA}$ ) was correlated with the magnitude of discharge in response to the CS $(r=-0.264, p<$ 0.01 ). Cells with higher levels of discharge in response to the CS required lower threshold levels of injected current for spike generation than cells with smaller responses to the CS during adaptation as well as conditioning.

Although an increased excitability was found with behavioral states in which the $\mathrm{CR}$ was performed, the degree of increase in excitability after conditioning was much the same in CSresponsive $(\geq 2 Z)$ cells as in "unresponsive" $(<2 Z)$ cells (Fig. 6 ). However, the number of cells with a magnitude of response $>3 Z$ above baseline activity and a high magnitude of excitability ( $<0.7 \mathrm{nA}$ required for spike generation) was greatly increased after conditioning relative to adaptation (Table $3 ; \chi^{2}, p$ $<0.01$ ). Thus, a major conscquencc of conditioning was an increase in the population of highly excitable CS-responsive cells.

Although low levels of threshold current (the measure of excitability) were correlated with high values of $R_{N}$ over the entire cell population, this correlation was not maintained in cells with a high magnitude of response to the CS. The $R_{N}$ of cells with response to the $\mathrm{CS}>3 Z$ above the magnitude of baseline activity was slightly reduced after conditioning (Fig. 6, middle right).

\section{Membrane properties and firing patterns as a function of motor projection}

Membrane properties were studied as a function of the motor projection of the cells (Fig. 7). A cell was classified as eye projective (or nose projective) if EMG activity recorded from the orbicularis oculi muscles (or levator oris muscles) was related 

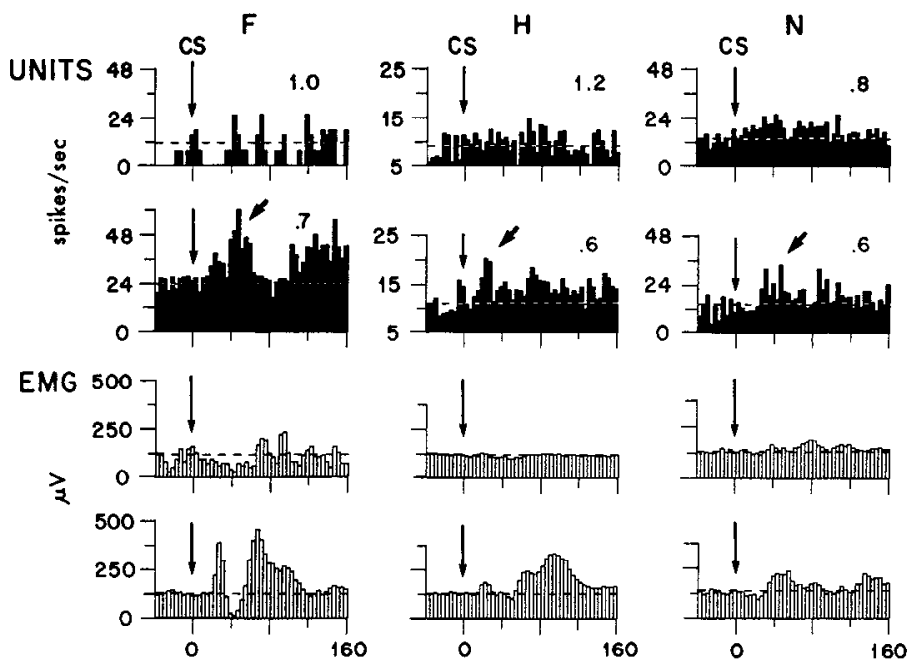

ms

to its spike discharge and exceeded baseline EMG activity (see Materials and Methods). A cell was classified as "both" projective if EMG activity recorded from both orbicularis oculi muscles and levator oris muscles was increased. Cells of the aforementioned classifications constituted the "projective" group of cells, identified as projecting, polysynaptically, to facial musculature. The remaining cells were classified as "unprojective" even though they may have projected to other muscles.

The proportion of projective and unprojective cells ( $42 \%$ and $58 \%$, respectively; adaptation) remained essentially unchanged after conditioning ( $47 \%$ and $53 \%$, respectively). The proportion of CS-responsive cells (including those with high excitability) increased from $43 \%$ to $73 \%$ among projective cells after conditioning, but not ( $54 \%$ to $48 \%$ ) among unprojective cells (difference in numbers of cells: $\chi^{2}, p<0.01$ ). Excitability increases occurred after conditioning in each group of cells irrespective of motor projection (Fig. 7, top).

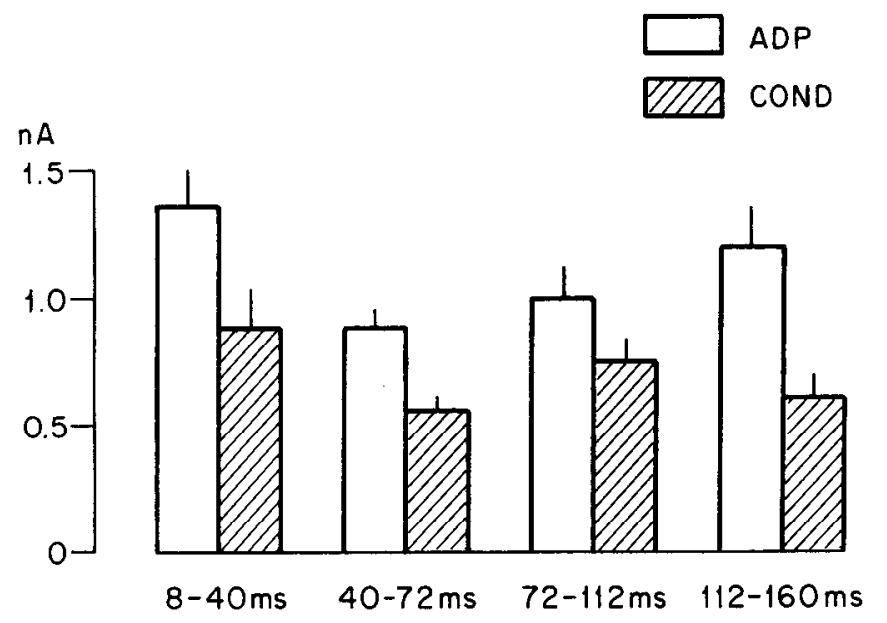

Peak Latency Period of Unit Response

Figure 5. Differences before (open bars, ADP) and after (shaded bars, $C O N D$ ) conditioning in mean excitability of neurons classified by latency of peak spike response to CS. (Excitability is defined by nanoamperes of depolarizing current required to produce spiking.) Thin vertical bars show SEM. Numbers of cells tested (ADP and COND, respectively) $-8-40$ msec: 19,$15 ; 40-72$ msec: 11,$16 ; 72-112$ msec: 8,14 112-160 msec: 7,5 .
Figure 4. Histograms of unit activity (solid bars) and associated EMG activity from left orbicularis oculi muscles (open bars) obtained from four cats $(F$, $H, N, G)$ before conditioning $(A D P)$ and after conditioning (COND). Times of delivery of click CS are shown by vertical arrows. Diagonal arrows designate increased spike response to CS after conditioning. Broken lines are mean baseline levels of activity in the 380 $\mathrm{msec}$ period prior to CS delivery. (Further details as in Aou et al., 1992.) The corresponding measurements of excitability thresholds (nA) of these cells are shown at right of histograms.

The eye-projective cells of the conditioned animals (see Fig. 7 , middle) had the highest mean $R_{N}$ of any group of cells classified by motor projection or CS receptivity, and the activity of these cells in response to click CS increased markedly after
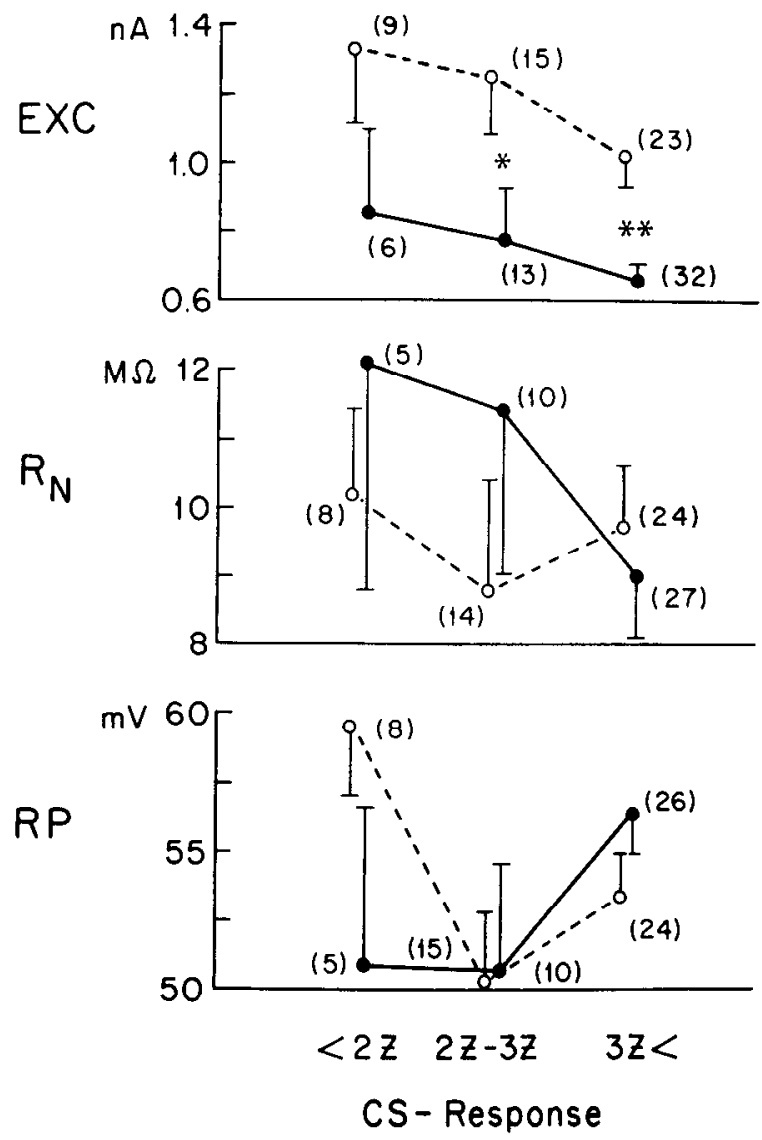

Figure 6. Excitability $(E X C)$, input resistance $\left(R_{N}\right)$, and RP as a function of CS responsiveness. (These variables are defined as in previous figures and text: $<2 Z$, cells that showed $<2 Z$ increase in discharge to the CS above baseline activity; $2 Z-3 Z$, cells that showed $2 Z$ to $3 Z$ increase in discharge; $>3 Z$, cells that showed $>3 Z$ increase in discharge.) Open circles, before conditioning; solid circles, after conditioning. Numbers in parentheses indicate number of cells tested. Vertical bars are SEM. 

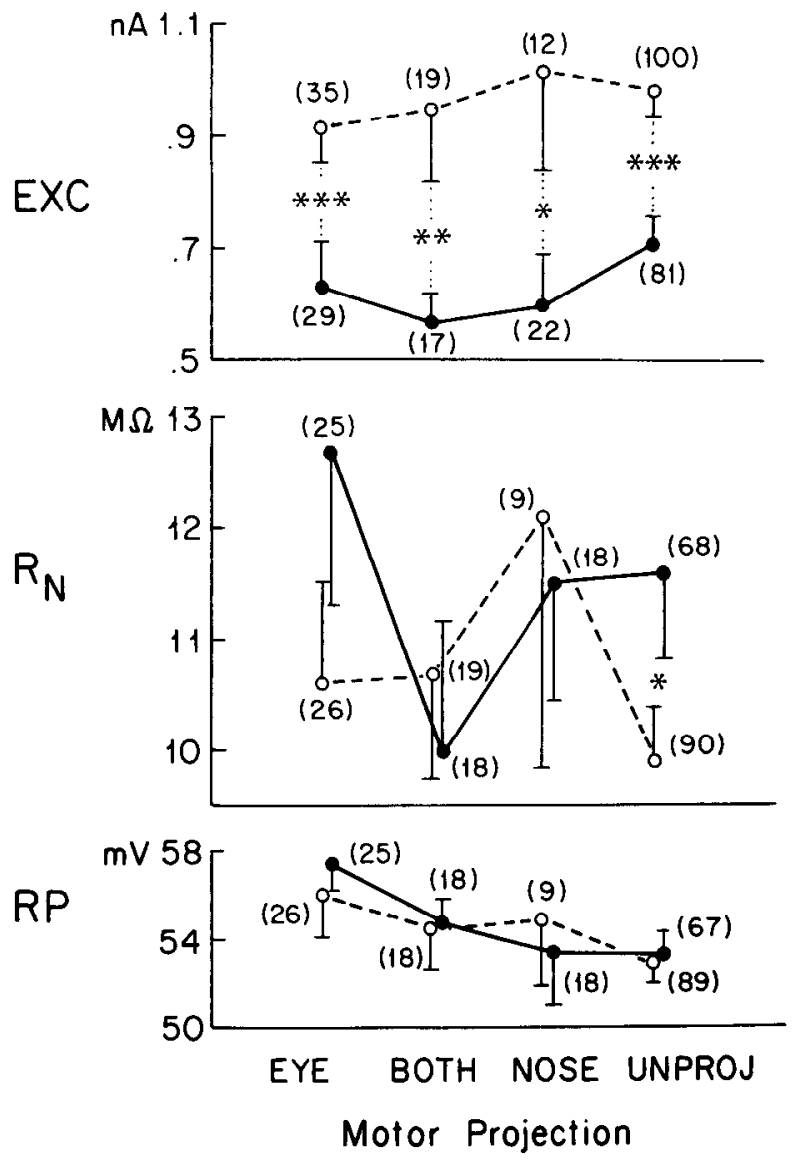

Figure 7. Excitability $(E X C)$, input resistance $\left(R_{N}\right)$, and RP as a function of motor projection. $E Y E$, eye-projective cells; $B O T H$, both eyeand nose-projective cells; NOSE, nose-projective cells; $U N P R O J$, nonprojective cells. Open circles, before conditioning; solid circles, after conditioning. Numbers in parentheses indicate number of cells tested. Vertical bars are SEM.

conditioning (Fig. 8). Cells of other facial motor projection did not show increases in $R_{N}$ after conditioning (Fig. 7); the unprojective cells showed an increase in $R_{N}$. Mean RP did not change as a function of motor projection after conditioning (Fig. 7, bottom).

\section{Discussion}

\section{Excitability increases after conditioning}

Our results provide evidence that increases in excitability to depolarizing current pulses occur in neurons of the motor cortex of cats following rapidly acquired Pavlovian conditioned blinking. Measurements of excitability and other neuronal membrane properties have not previously been made after conditioning in animals with rapidly acquired blink responses. Rapid acquisition of the CR permitted measurement of membrane properties in the same animals before and after conditioning. After conditioning, the mean level of depolarizing current required to elicit spiking decreased in each animal studied (Fig. 2).

Relationship of excitability increase to order of stimulus presentation and performance of $C R$. The increases in neural excitability depended on the order of stimulus pairing. Forward pairing of HS with click CS and tap US led to development of conditioned eye blink responses and greater increases in excitability. Excitability was also related to the degree of retention
EYE-PROJECTIVE
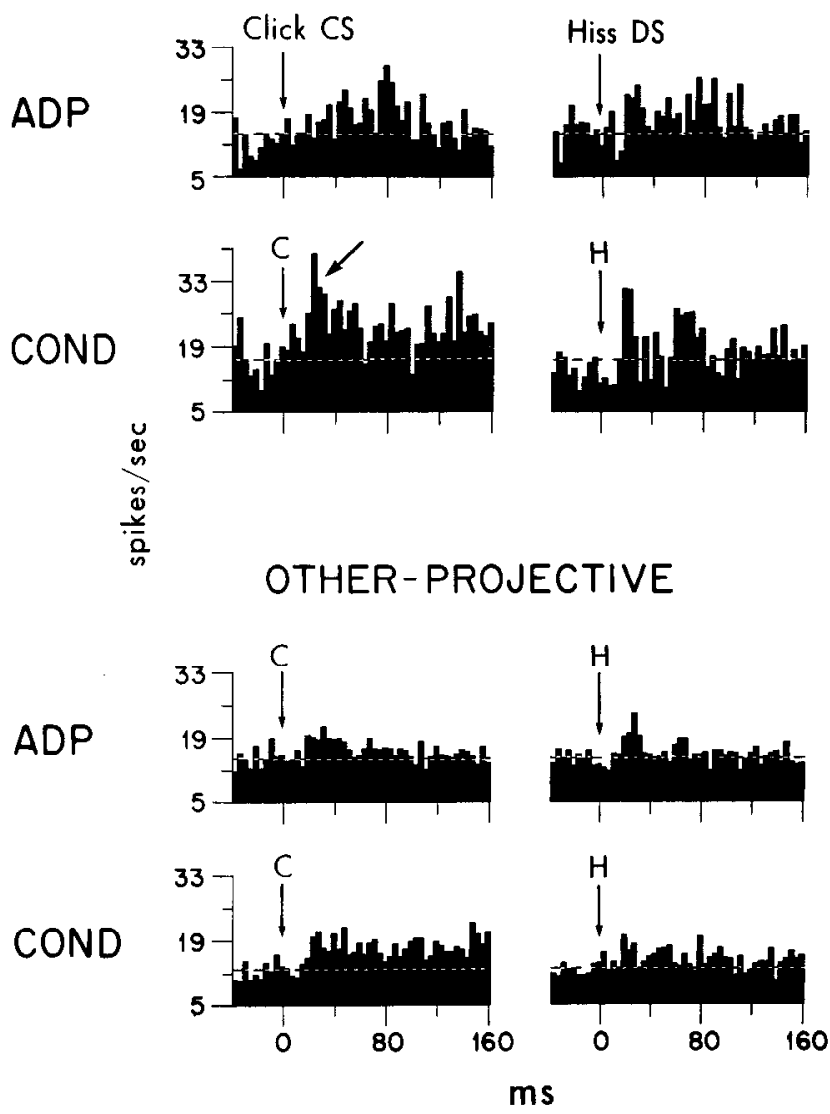

Figure 8. Histogram averages of spike activity of units separated according to motor projection (see text). (Eye-projective units had spikesynchronized EMG activity elicited in left orbicularis oculi muscles.) $A D P$, adaptation, before conditioning; $C O N D$, after conditioning. Other labeling is as in Figure 4.

of performance of blink CRs. Increases in excitability above naive levels were found after periods of prolonged extinction when the CR was retained (EXT $\mathrm{S}^{+}$). [Cells of cats given comparable numbers of extinction trials with loss or substantial reduction of performance of CRs (EST S-) showed levels of excitability nearer those of the naive state (Table 2).] These findings support the conclusion that the increased excitability of these cells helped promote elaboration of the conditioned response.

Possible mechanisms underlying increased excitability. Several biophysical mechanisms might produce an increased postsynaptic neuronal excitability: (1) a decrease in the critical firing threshold for eliciting spike potentials, (2) a depolarization of the level of RP, (3) an increase in $R_{N}$ causing a change in cable spread of postsynaptic potentials (Woody and Black-Cleworth, 1973), and (4) a change in a transient current that was activated by depolarization (Alkon, 1979, 1984; Rudy, 1988; Woody et al., 1991).

Our data allow inferences to be drawn about the likelihood of operation of some of the above mechanisms, though not about other mechanisms presynaptic to these cells (e.g., Kandel and Schwartz, 1982; Bliss et al., 1986). [E.g., presynaptic mechanisms could explain a selectively increased response to the CS (relative to the response to the DS) in the cells classified as 
responsive to both CS and DS after conditioning (see Aou et al., 1992, their Fig. 8). Alternatively, those cells had an increased postsynaptic excitability after conditioning (mean $0.8 \mathrm{nA}$, conditioning, vs. $1.2 \mathrm{nA}$, adaptation) and could have had a selective increase in postsynaptic conductances nearby synapses activated by the CS (Barrionuevo et al., 1986; Malenka et al., 1986; Baranyi and Szente, 1987).]

It was unlikely that a change in RP or critical firing threshold was the mechanism responsible for the increased neuronal excitability because no significant differences in RP or spontaneous firing rate were found between adaptation and conditioning states. Depolarization of the RP may have explained the increased rates of spontancous firing after backward conditioning (Aou et al., 1992, their Fig. 6, DHS $)$. Changes in afterhyperpolarizations (AIIPs) have been reported after conditioning (Sanchez-Andres and Alkon, 1991; cf. Alkon, 1979) and after HS (Aou et al., 1988), but in the present study, there were insufficient cells with AHPs to determine if there were changes in this variable.

Earlier evidence has suggested that increases in apparent $R_{N}$ occur to support conditioning in cats (Woody and Black-Cleworth, 1973; Brons and Woody, 1980; Matsumura and Woody, 1986) and other genera (Woolacott and Hoyle, 1976; Alkon, 1979). Increases in excitability and input resistance measured by depolarizing pulses in cells of the motor cortex of cats have been hypothesized to support the specificity of performance of the CR (Woody and Engel, 1972, Woody and Black-Cleworth, 1973; Brons and Woody, 1980). In the present study, increased $R_{N}$ was significantly correlated with increased excitability. Therefore, an increase in $R_{N}$ could have been one mechanism supporting the excitability increase after conditioning. Increases in $R_{N}$, however, werc less robust than the changes in excitability after conditioning. This could be because some changes in $R_{N}$ were orthogonal to the changes in excitability or because establishment of changes in $R_{N}$ is difficult since $R_{N}$ varies with the size of cell, the locus of the cell penetrated (soma vs dendrites), and the degree of activated membrane conductances. The increases in $R_{N}$ were also less dependent on a forward order of stimulus pairing and were less well related to the ability to perform blink CRs than were the increases in neural excitability (Table 2).

\section{Role of motor cortex in short-and long-latency conditioned blinking}

Analysis of unit activity and excitability by latency of unit response to the CS suggested that long- as well as short-latency conditioned blinking was mediated by cells of the motor cortex. The motor cortex has becn shown to be nccessary and (with its descending projections) sufficient for the production of shortlatency blink CRs (Woody and Brozek, 1969; Woody and Yarowsky, 1972; Woody et al., 1974).

Excitability increase in short-and long-latency CS-responsive cells. Excitability increases were found that supported increased spike activity at $\alpha_{1}(8-40 \mathrm{msec}), \alpha_{2}(40-72 \mathrm{msec}), \beta(72-112$ msec), and $\gamma(112-160 \mathrm{msec})$ latencies after delivery of the CS (see Fig. 5 and Aou et al., 1992), and the proportion of cells that were highly responsive to the CS increased at each latency after conditioning. Given a conduction delay of 7-8 $\mathrm{msec}$ between the motor cortex and the periphery (Woody et al., 1970; Woody and Yarowsky, 1972), these latencies of spike activation would support initiation of each component of the compound blink CR. The later components of the $\mathrm{CR}$ were additionally supported by increases in late components of activity in the same cells that showed increases in excitability and enhancement of earlier components of CS-elicited activity after conditioning (see Aou et al., 1992).

\section{Slow and rapid conditioning and sensitization}

The increases in activity and neural excitability after rapid eye blink conditioning resembled earlier findings (Woody and BlackCleworth, 1973; Brons and Woody, 1980) after acquisition of a slowly developing blink CR using the same click CS and tap US without addition of HS. Specifically referable to conditioning were the increases in the proportion of CS-excitable cells and the magnitude of excitability and CS-evoked activity. It seems noteworthy that comparable changes in unit activity and excitability can be found after two conditioning procedures in which the rate of conditioning differs by almost 2 orders of magnitude.

The possibility should be considered that similar mechanisms involving increased neural excitability underlie both rapidly and slowly acquired forms of eye blink conditioning and that, by decreasing the time required for the excitability increases to occur, the conditioning process may be accelerated. Sensitization occurs in early stages of rapid conditioning (Kim et al., 1983; Woody et al., 1983) and could play a role in accelerating development of the CR. Both CS-responsive and -unresponsive cells showed an increased excitability as soon after rapid conditioning as excitability could be tested (Fig. 6). These increases occurred rapidly and, as described earlier, were equivalent in magnitude early (first five cells) and late (last five cells) after (initial) conditioning. The smaller increases were nonspecific with respect to receptivity of the cells to CS and DS and were thus attributable to nonspecific effects of sensitization manifest in early conditioning trials. They could casily have been the forerunners of the larger and more CS-specific increases in excitability that supported the ability to discriminate the CS from the DS when performing the conditioned blink movement.

\section{Mechanisms supporting enhanced response to the CS}

Overall, the greater the excitability of units of the motor cortex to depolarizing current, the larger was the magnitude of their response to the CS (Fig. 6). When we examined the group of highly excitable cells ( $<0.7 \mathrm{nA}$ of threshold current), an increase in the number of such cells was found after conditioning among the population of CS-responsive cells (Table 3 ). Specific effects of conditioning on excitability that led to enhancement of spike activity and production of the CR in response to the CS were expressed as a change in the proportion of this group of cells. [As noted elsewhere (Aou et al., 1992), the overall population of CS-rcsponsive cclls also increased after conditioning.]

Since the highly excitable CS-responsive cells did not have an increased $R_{N}$ after conditioning, a mechanism other than increased postsynaptic resistance measured by hyperpolarizing pulses must have contributed to their increased excitability and magnitude of discharge. This mechanism, as yet unidentified, increased the postsynaptic response to depolarizing potentials and increased the efficacy of transmission of the CS without producing a change in RP, spontaneous firing rate, or steady state $R_{N}$. A reduction in a rapidly activated, transient component of an outward potassium current such as the A-current (Alkon, 1979; Woody et al., 1989, 1991) would satisfy such observations. Recent observations indicate that the A-current may be activated at the resting potential of hippocampal neurons (Saint et al., 1990). (An increase in an activated sodium current might also have increased excitability but would likely have increased 
spontaneous firing due to the positive equilibrium potential of sodium.)

\section{Mechanisms supporting production of the $C R$}

The proportion of projective and unprojective cells remained unchanged after conditioning; however, the proportion of CSresponsive cells (including those with high excitability) increased among motor-projective cells (from $43 \%$ to $73 \%$ ) but not among unprojective cells. Thus, an additional cellular mechanism supporting development of the CR appeared to be expressed as a change in the proportion of CS-responsive, motorprojective cells.

Substantial increases in short-latency, CS evoked activity were found after conditioning in units that projected, polysynaptically, to the eye muscles involved with production of the conditioned eye blink movement (Fig. 8), and the highest values of $R_{N}$ were found in these eye-projective cells after conditioning. [Although the number of cells was too small to confirm a significant increase in $\boldsymbol{R}_{N}$ relative to adaptation, the mean value of $R_{N}$ in this group (Fig. 7) was higher than that in the numerically larger group of "unprojective" cells in which a significant increase in $R_{N}$ was found after conditioning.] HS produced abdominal muscle contractions as well as facial (blink) movements. Both the increased $R_{N}$ in the "unprojective" cells and the more broadly increased neural excitability (Fig. 7) may be attributable to the addition of HS to the tap US with the production of unconditioned motor responses in muscles besides those involved with eye blink. Since local ionophoretic application of glutamate can be used in lieu of HS to produce conditioning of cortical units (Woody et al., 1991), the activation of nonspecific neuromodulatory pathways may also have contributed to the less specific changes in excitability of motorprojective cells found here versus those found in earlier studies of conditioning without HS (Woody and Engel, 1972).

Specific features of conditioning, such as the discriminative response to the CS and production of the blink CR, appeared to be supported by increases in the number of highly excitable CS-responsive cells, in the number of CS-responsive motorprojective cells, and by an increased $R_{N}$ in eye-projective cells.

\section{References}

Alkon DL (1979) Voltage-dependent calcium and potassium ion conductances: a contingency mechanism for an associative learning model. Science 205:810-816.

Alkon DL (1984) Calcium-mediated reduction of ionic currents: a biophysical memory trace. Science 226:1037-1045.

Aou S, Oomura Y, Woody CD, Nishino H (1988) Effects of behaviorally rewarding hypothalamic electrical stimulation on intracellularly recorded neuronal activity in the motor cortex of awake monkeys. Brain Res 439:31-38.

Aou S, Woody CD, Birt D (1992) Changes in the activity of units of the cat motor cortex with rapid conditioning and extinction of a compound eye blink movement. J Neurosci 12:549-559.

Baranyi A, Szente MB (1987) Long-lasting potentiation of synaptic transmission requires postsynaptic modifications in the neocortex. Brain Res 423:378-384.

Baranyi A, Szente MB, Woody CD (1988) Activation of protein kinase $C$ induces long-term changes of postsynaptic currents in neocortical neurons. Brain Res 440:341-347.

Barrionuevo G, Kelso SR, Johnston D, Brown TH (1986) Conductance mechanism responsible for long-term potentiation in monosynaptic and isolated excitatory synaptic inputs to hippocampus. J Neurophysiol 55:540-550.

Berthier N, Woody CD (1988) In vivo properties of neurons of the precruciate cortex of cats. Brain Res Bull 21:385-393.
Bliss TVP, Douglas RM, Errington ML, Lynch MA (1986) Correlation between long-term potentiation and release of endogenous amino acids from dentate gyrus of anaesthetized rats. J Physiol (Lond) 377: $391-408$.

Brons JF, Woody CD (1980) Long-term changes in excitability of cortical neurons after Pavlovian conditioning and extinction. $J$ Neurophysiol 44:605-615.

Creutzfeldt OD, Lux HD, Nacimiento AC (1964) Intracellulare Reizung corticaler Nervenzellen. Pfluegers Arch 281:129-151.

Hilgard ER, Marquis DG (1940) Conditioning and learning. New York: Appleton-Century-Crofts.

Hirano T, Woody C, Birt D, Aou S, Miyake J, Nenov V (1987) Pavlovian conditioning of discriminatively elicited eyeblink responses with short onset latency attributable to lengthened interstimulus intervals. Brain Res 400:171-175.

Kandel ER, Schwartz JH (1982) Molecular biology of learning: modulation of transmitter release. Science 218:433-443.

Kim EH-J, Woody CD, Berthier NE (1983) Rapid acquisition of conditioned eye blink responses in cats following pairing of an auditory CS with glabella tap US and hypothalamic stimulation. J Neurophysiol 49:767-779.

Koike H, Okada Y, Oshima T, Takahashi K (1968) Accommodative behavior of cat pyramidal tract cells investigated with intracellular injection of currents. Exp Brain Res 5:173-188.

Krnjević K, Pumain R, Renaud L (1971) The mechanism of excitation by acetylcholine in the cerebral cortex. J Physiol (Lond) 215:247268.

Lux HD, Pollen DA (1966) Electrical constants of neurons in the motor cortex of the cat. J Neurophysiol 29:207-220.

Malenka RC, Madison DV, Nicoll RA (1986) Potentiation of synaptic transmission in the hippocampus by phorbol esters. Nature $321: 175$ 177.

Matsumura M, Woody CD (1986) Long-term increases in excitability of facial motoneurons and other neurons in and near the facial nuclei after presentations of stimuli leading to acquisition of a Pavlovian conditioned facial movement. Neurosci Res 3:568-589.

Moore JW, Desmond JE, Berthier NE (1982) The metencephalic basis of the conditioned nictitating membrane response. In: Conditioning: representation of involved neural functions (Woody CD, ed), pp 459482. New York: Plenum.

Purves RD (1981) Microelectrode methods for intracellular recording and iontophoresis. London: Academic.

Rudy B (1988) Diversity and ubiquity of $K$ channels. Neuroscience 25:729-749.

Saint DA, Thomas T, Gage PW (1990) $\mathrm{GABA}_{B}$ agonists modulate a transient potassium current in cultured mammalian hippocampal neurons. Neurosci Lett 1 18:9-13.

Sanchez-Andres JV, Alkon DL (1991) Voltage-clamp analysis of the effects of classical conditioning on the hippocampus. J Neurophysiol 65:796-807.

Spain WJ, Schwindt PC, Crill WE (1987) Anomalous rectification in neurons from cat sensorimotor cortex in vitro. J Neurophysiol 57: $1555-1576$

Stafstrom CE, Schwindt PC, Flatman JA, Crill WE (1984) Properties of subthreshold response and action potential recorded in layer $\mathrm{V}$ neurons from cat sensorimotor cortex in vitro. $\mathrm{J}$ Neurophysiol 52: 244-263.

Thompson RF (1986) The neurobiology of learning and memory. Science 233:941-947.

Thompson RF, Donegan NH (1987) Learning and memory. In: Encyclopedia of neuroscience, Vol II (Adelman G, ed), pp 571-574. New York: Birkhauser Boston.

Winer BJ (1971) Statistical principles in experimental design, 2d Ed. New York: MacGraw.

Woody C, Yarowsky P, Owens I, Black-Cleworth P, Crow T (1974) Effect of lesions of cortical motor areas on acquisition of conditioned eyeblink in the cat. J Neurophysiol 37:385-394.

Woody CD (1982) Memory, learning, and higher function: a cellular view, pp 1-483. New York: Springer.

Woody CD (1986) Understanding the cellular basis of memory and learning. Annu Rev Psychol 37:433-493.

Woody CD, Black-Cleworth P (1973) Differences in excitability of cortical neurons as a function of motor projection in conditioned cats. J Neurophysiol 36:1104-1116.

Woody CD, Brozek G (1969) Changes in evoked responses from facial 
nucleus of cat with conditioning and extinction of an eye blink. $\mathrm{J}$ Neurophysiol 32:717-726.

Woody CD, Engel J Jr (1972) Changes in unit activity and thresholds to electrical microstimulation at coronal-pericruciate cortex of cat with classical conditioning of different facial movements. J Neurophysiol 35:230-241.

Woody CD, Yarowsky PJ (1972) Conditioned eye blink using electrical stimulation of coronal-precruciate cortex as conditional stimulus. J Neurophysiol 35:242-252.

Woody CD, Vassilevsky NN, Engel J Jr (1970) Conditioned eye blink: unit activity at coronal-precruciate cortex of the cat. J Neurophysiol 33:851-864.

Woody CD, Knispel JD, Crow TJ, Black-Cleworth PA (1976) Activity and excitability to electrical current of cortical auditory receptive neurons of awake cats as affected by stimulus association. J Neurophysiol 39:1045-1061.

Woody CD, Kim EH-J, Berthier NE (1983) Effects of hypothalamic stimulation on unit responses recorded from neurons of sensorimotor cortex of awake cats during conditioning. J Neurophysiol 49:780791.

Woody CD, Gruen E, McCarley K (1984) Intradendritic recording from neurons of motor cortex of cats. J Neurophysiol 51:925-938.

Woody CD, Baranyi A, Szente MB, Gruen E, Holmes W, Nenov V, Strecker GJ (1989) An aminopyridine-sensitive, early outward current recorded in vivo in neurons of the precruciate cortex of cats using single-electrode voltage-clamp techniques. Brain Res 480:72-81.

Woody CD, Gruen E, Birt D (1991) Changes in membrane currents during Pavlovian conditioning of single cortical neurons. Brain Res 539:76-84.

Woolacott MH, Hoyle G (1976) Membrane resistance changes associated with single, identified neuron learning. Soc Neurosci Abstr 2: 339.

Yeo CH, Hardiman MJ, Glickstein M (1984) Discrete lesions of the cerebellar cortex abolish the classically conditioned nictitating membrane response of the rabbit. Behav Brain Res 13:261-266. 